\title{
Oral candidal colonization in immunocompromised patients
}

\author{
Zahraa S. Kasim *, Manahil M. Yehia** \\ *Department of Clinical Laboratory Sciences, College of Pharmacy, University of Mosul, Mosul, Iraq. \\ **Department of Microbiology, College of Medicine, University of Mosul, Mosul, Iraq.
}

$\begin{array}{lll}\text { ABSTRACT } & \frac{\text { Received }}{11.6 .2012} \quad \frac{\text { Accepted }}{16.5 .2013}\end{array}$

Objective: 1. To identify Candida species isolated from saliva of predicatively immunocompromised (cancer, diabetic) patients and control group. 2. To test the susceptibility of all the isolated yeasts against 6 antifungal agents, namely amphotericin B, nystatin, fluconazole, ketoconazole, voriconazole and itraconazole. 3. Then to compare the growth and density of yeasts from immunocompromised patients to those from healthy control group.

Patients and Methods: This study included 120 saliva samples from immunocompromised patients, 60 of them with cancer and under treatment, the other 60 patients have uncontrolled diabetes mellitus, attending the Al-Wafa'a Center for diabetic patients and the consultative clinic of Oncology and Nuclear Medicine Hospital. The clinical specimens were collected during the period from January-June 2011. In addition to 60 saliva samples from a healthy individuals. The identification of the isolated yeasts was carried by fluorescent and/or light microscope, culture on different types of media, biochemical tests and API-20 C system. Susceptibility test to six antifungal agents was prepared for each isolate.

Results: Eighty seven $(72.5 \%)$ patients showed the presence of yeasts in their saliva in comparison to $18(30 \%)$ from the control group. Eighty four isolates from genus Candida identified into 8 species mainly $\mathrm{C}$. albicans. The isolates showed the best susceptibility to amphotericin B.

Conclusions: A higher frequency of yeasts were detected in the immunocompromised patients in comparison to the control group. This is considered a risk factor for infection. Candida albicans is the main isolate but there was a shift to non -albicans Candida spp. in immunocompromised patients. This means that are more resistant to antifungal agents.

Keywords: Candidal colonization, immunocompromised patients.

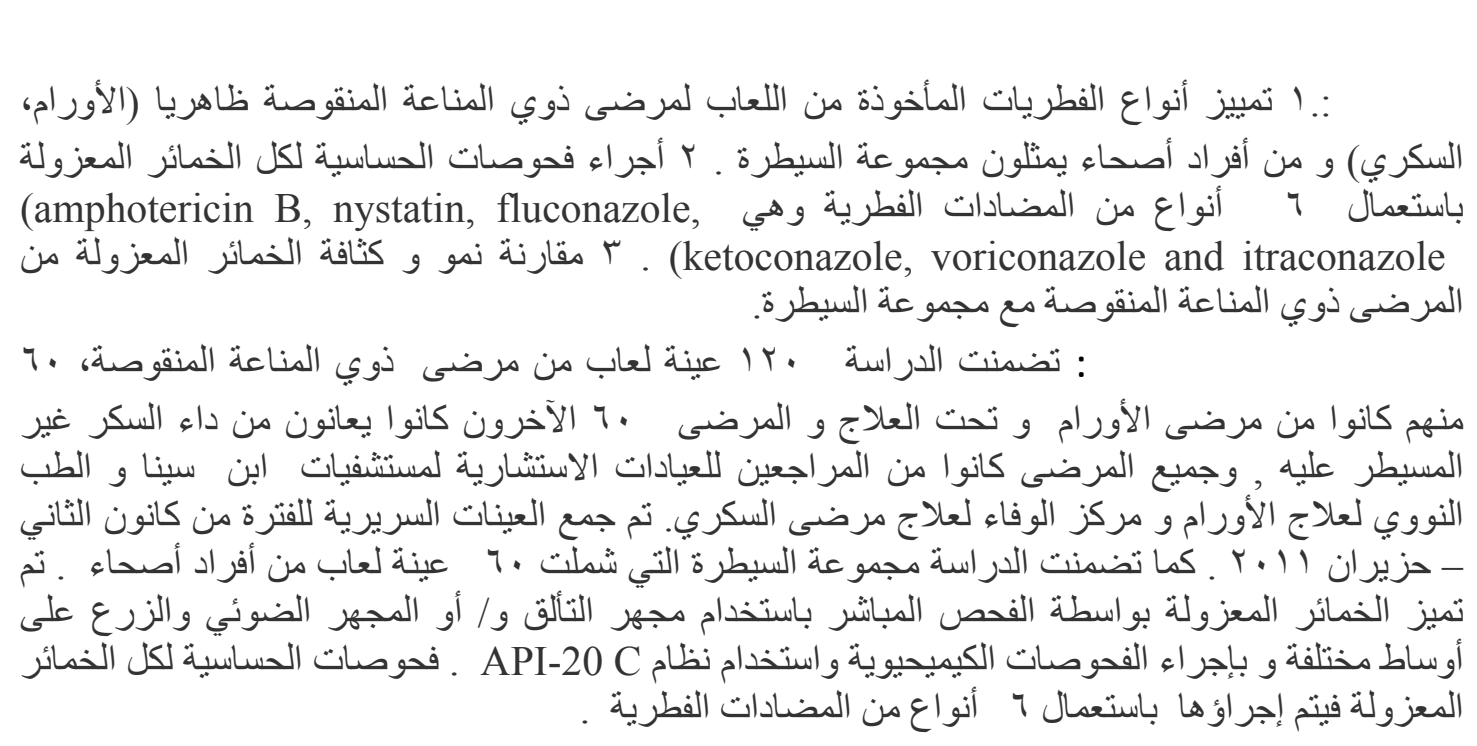




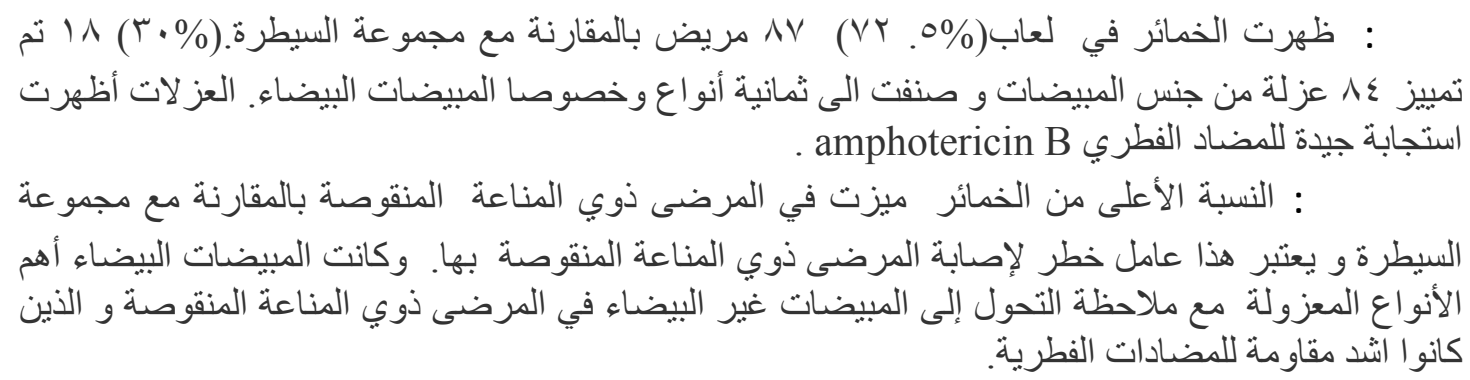

$C$ andida species is present in oral 1 cavity in about half of the population without causing disease ${ }^{1}$. Asymptomatic carriage may cause a high risk for Candida infection in immunosuppressed patients ${ }^{2}$. Any factors causing microbiota disequilibrium or mucosal lesion, increase colonization by Candida ${ }^{3}$.

The transformation of Candida from a harmless, obscure commensal to a hypervirulent pathogen under the conditions of dysfunctional host defense system is attributed to the expression of virulence determinants, including elaboration of hydrolytic enzymes, secreted aspartyl proteinase and phospholipase ${ }^{4}$. Recently, it has been reported that there is a shift in the dominant causative agent from Candida albicans to non-albicans Candida spp. including C. parapsilosis, C. glabrata, C .tropicalis and others ${ }^{5}$.

Colonization of Candida is more prevalent in diabetic patients ${ }^{6}$. The induced diabetic state was associated with increased susceptibility to infection by Candida species ${ }^{7}$. Furthermore, Candida spp. remain the most common fungal infection in patients with cancer ${ }^{8}$ The chemotherapeutic agents are toxic and target malignant and normal cells mostly of the oral and gastrointestinal mucosa ${ }^{9}$.

Numerous antifungal agents have been developed, and newer agents are on horizon. This is due to the increased resistance of organisms to the antifungal drugs which leads to the development of newer agents ${ }^{10}$.

\section{Patients and methods}

The studied individuals were 120 predicatively immunocompromised patients including $60(50 \%)$ cancer patients under treatment with chemotherapy and 60 (50\%) uncontrolled diabetic patients of $>5$ years duration ( their fasting blood sugar more than $200 \mathrm{mg} / \mathrm{dl}$ ). The males were $54(45 \%)$ and females were $66(55 \%)$ and their age ranged from $1-80$ (mean $\pm \mathrm{SD}=51.48 \pm 16.42$ ) years.

On the other hand, 60 apparently healthy individuals were included during the study as a control group. These individuals were sex and age matches with the immunocompromised patients.

\section{The studied samples}

A total of 120 saliva samples were collected from the patients in Alwafa'a center for diabetes and consultative clinic of Oncology and Nuclear Medicine Hospital. Moreover, saliva samples were obtained from 60 normal individuals as a control.

Saliva samples were collected in early morning from patients and control group in dry sterile wide mouth containers. The samples brought to the laboratory without any delay.

\section{Processing of the clinical samples and isolation of yeasts}

A loopful (0.1) of saliva from each sample was inoculated on Sabouraud's agar with chloramphenicol and the same on brain-heart infusion (B.H.I) 
blood agar. The plates were incubated at $37^{\circ} \mathrm{C}$ for $2-3$ days, and discarded after 5 days if no growth.

Two smears were prepared from each specimen. The first slide was heat fixed and stained by Gram's staining method. The second wet mounted slide with a drop of $20 \% \mathrm{KOH}$ solution with glycerin and drop of calcofluor solution, then examined under fluorescent microscope ${ }^{11}$.

For the identification of the isolates, different tests were used including germ tube test, chlamydospore formation test, lactophenol mount, and API-20 C system ${ }^{12,13}$.

\section{Antibiogram test}

Disk diffusion method was used to determine the susceptibility of isolated Candida spp. against 6 antifungal agents namely nystatin, amphotericin B, fluconazole, voriconazole, itraconazole and ketoconazole.

A tested yeast suspension was compared to $0.5 \mathrm{McF}$ arland scale, then inoculate onto the surface of MullerHinton agar plates. After 2-3 minutes, the antifungal disks were placed firmly on the surface of the inoculated plates. The plates were incubated for 24-48 hour at $37^{\circ} \mathrm{C}$.

\section{Stastical analysis}

The test used for statsical analysis.

1. Chi-Square test

2. Z- test

3. Mann-Whitney test

4. t-test

\section{Results}

Among the 120 patients, there were $87(72.5 \%)$ who showed the presence of yeasts in their saliva in comparison to $18(30 \%)$ of the 60 control group with a significant difference between them $(\mathrm{p}<0.001)$.

From the 87 patients with positive yeast isolates $46(52.9 \%)$ of them were cancer patients, and Candida spp. isolates from $41(47.1 \%)$ of them. On the other hand, from the 41 diabetic patients with positive yeast isolate 40 (46\%) of them showed Candida spp. in their saliva. Other non- Candida yeast isolate were detected from $5(5.7 \%)$ cancer patients and one (1.2\%) diabetic patients. Eighteen healthy individuals showed Candida spp. in their saliva. Mixed Candida spp. were identified from 2 samples from cancer patients and one sample of diabetic patient with no significant in the presence of yeasts in cancer and diabetic patients (Table1).

\section{Candidal colonization}

The mean value of yeast density colony forming unit (CFU) was 10020.1 in the saliva of patients and 772.2 in the saliva of control group, with a significantly difference between them $(\mathrm{P}<0.001)$.

The diabetic patients who were Candidal carriers in their saliva, harbored the yeasts in higher density than the cancer patients. On the other hand, the densities of Candida in the saliva of cancer and diabetic patients were higher than the control carriers (Fig 1).

\section{The isolated yeasts}

Different tests were used to identify the yeasts including direct examination of the clinical specimens (Fig 2), then culture, germ tube, chlamydospore formation test, and API- $20 \mathrm{C}$ system.

The 84 isolates of genus Candida from cancer and diabetic patients were identified into 8 species representing Candida albicans (67/ 84, 79.8\%) ; C. glabrata $(5 / 84,5.9 \%)$; C.famata $(3 / 84$, $3.6 \%)$ C. cifferrii (3/84, 3.6\%); C.parapsilosis $\quad(2 / 84 \%, \quad 2.4 \%)$; C.guilliermondii (1/84, 1.1\%); C. kefyr $(2 / 84,2.4 \%)$; C.krusei $(1 / 84,1.1 \%)$. Furthermore, out of the 90 total yeasts isolate, 6 of them were non- Candida species namely Cryptococcus 
neoformans, Saccharomyces

C. cereviciae and Rhodotorula rubra with a significant difference between the species of $\mathrm{C}$. albicans and other Candida and yeast species $(\mathrm{P}<0.001)$, Table 2 .

For control group, 2 Candida species were identified from the 18 isolates. These were $\mathrm{C}$. albicans $(17 / 18,94.4 \%)$ and C. kefyr $(1 / 18,5.6 \%)$. Statistically, a significant difference was found between patients and control group in the presence of yeasts in their saliva ( $P$ 0.001), Table 2

\section{Susceptibility test}

The results of the sensitivity test showed that the most effective antifungal agents against the isolated yeasts from saliva in cancer and diabetic patients were amphotericin B $(86.4 \%, 100 \%)$ followed by nystatin $(81 \%, 91.6 \%)$; ketoconazole $(71.1 \%$, $88.1 \%)$; voriconazole $(62.6 \%, 66.3 \%)$; fluconazole $\quad(57.9 \%, 48.4 \%$, $) \quad$ least effective antifungal agents was itraconazole $\quad(23.4 \quad \%, 49 \quad \%)$ respectively. On the other hand, the yeasts from the control group showed $100 \%$ sensitivity to amphotericin B and nystatin followed by ketoconazole $(91.2 \%)$; voriconazole $\quad(88.3 \%)$; fluconazole $(85.3 \%)$ and itraconazole (79.4\%).

Table 1. The number and percentage of Candida species and other yeast species isolated from saliva of patients and control group.

\begin{tabular}{|c|c|c|c|c|c|c|}
\hline \multirow{2}{*}{$\begin{array}{c}\text { Types of } \\
\text { diseases }\end{array}$} & \multicolumn{2}{|c|}{ Patients } & \multicolumn{2}{c|}{ Candida isolates } & \multicolumn{2}{c|}{$\begin{array}{c}\text { Other yeast } \\
\text { isolates }\end{array}$} \\
\cline { 2 - 7 } & No. & $\%$ & No. & $\%$ & No. & $\%$ \\
\hline Cancer & 46 & 52.9 & $41^{*}$ & 47.1 & 5 & 5.7 \\
\hline Diabetic & 41 & 47.1 & $40^{* *}$ & 46 & 1 & 1.2 \\
\hline Total & 87 & 100 & 81 & 93.1 & 6 & 6.9 \\
\hline Control & 18 & 100 & 18 & 100 & - & - \\
\hline
\end{tabular}

* 2 Mixed Candida species, ** 1 Mixed Candida species

Note: There is no significant difference in the presence of yeasts in cancer and diabetic at $(\mathrm{p}<0.281)$ by Chi-square test. 
Table 2. Distribution of Candida species and other yeasts species in studied subject.

\begin{tabular}{|c|c|c|c|c|c|c|c|c|}
\hline \multirow{3}{*}{ Isolates } & \multirow{2}{*}{\multicolumn{2}{|c|}{$\begin{array}{l}\text { Total } \\
\text { isolates }\end{array}$}} & \multicolumn{4}{|c|}{ Patients } & \multirow{2}{*}{\multicolumn{2}{|c|}{$\begin{array}{l}\text { Control } \\
\text { group }\end{array}$}} \\
\hline & & & \multicolumn{2}{|c|}{ Cancer } & \multicolumn{2}{|c|}{ Diabetic } & & \\
\hline & No. & $\%$ & No. & $\%$ & No. & $\%$ & No. & $\%$ \\
\hline C. albicans & 67 & 74.4 & 33 & 36.7 & 34 & 37.8 & 17 & 94.4 \\
\hline C. glabrata & 5 & 5.6 & 2 & 2.2 & 3 & 3.4 & - & - \\
\hline C. famata & 3 & 3.3 & 1 & 1.1 & 2 & 2.2 & - & - \\
\hline C. cifferrii & 3 & 3.3 & 3 & 3.4 & - & - & - & - \\
\hline C.parapsilosis & 2 & 2.3 & 2 & 2.2 & - & - & - & - \\
\hline C.kefyr & 2 & 2.3 & - & - & 2 & 2.2 & 1 & 5.6 \\
\hline C. guilliermondii & 1 & 1.1 & 1 & 1.1 & - & - & - & - \\
\hline C.krusei & 1 & 1.1 & 1 & 1.1 & - & - & - & - \\
\hline C.neoformans & 1 & 1.1 & 1 & 1.1 & - & - & - & - \\
\hline C. laurentii & 3 & 3.3 & 2 & 2.2 & 1 & 1.1 & - & - \\
\hline S.cerevciae & 1 & 1.1 & 1 & 1.1 & - & - & - & - \\
\hline R. rubra & 1 & 1.1 & 1 & 1.1 & - & - & - & - \\
\hline Total & 90 & 100 & 48 & 53.3 & 42 & 46.7 & 18 & 100 \\
\hline
\end{tabular}

Note: There is a significant difference between the presence of Candida albicans and other yeast specie at $\mathrm{p}<0.001$ by Z-test.

There is a significant difference between patients and control in presence of yeast species in their clinical specimen at $\mathrm{p}<0.001$ by Mann-Whitney test. 


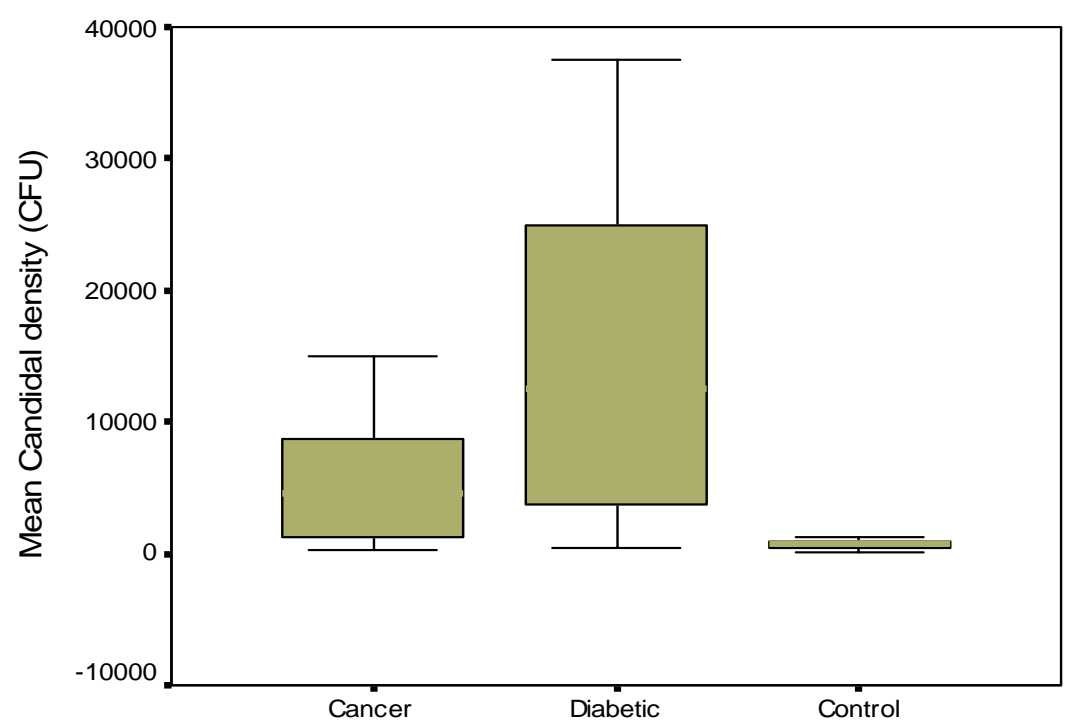

Groups of the studied subjects

Figure 1. Candidal density in saliva among the studied subjects.

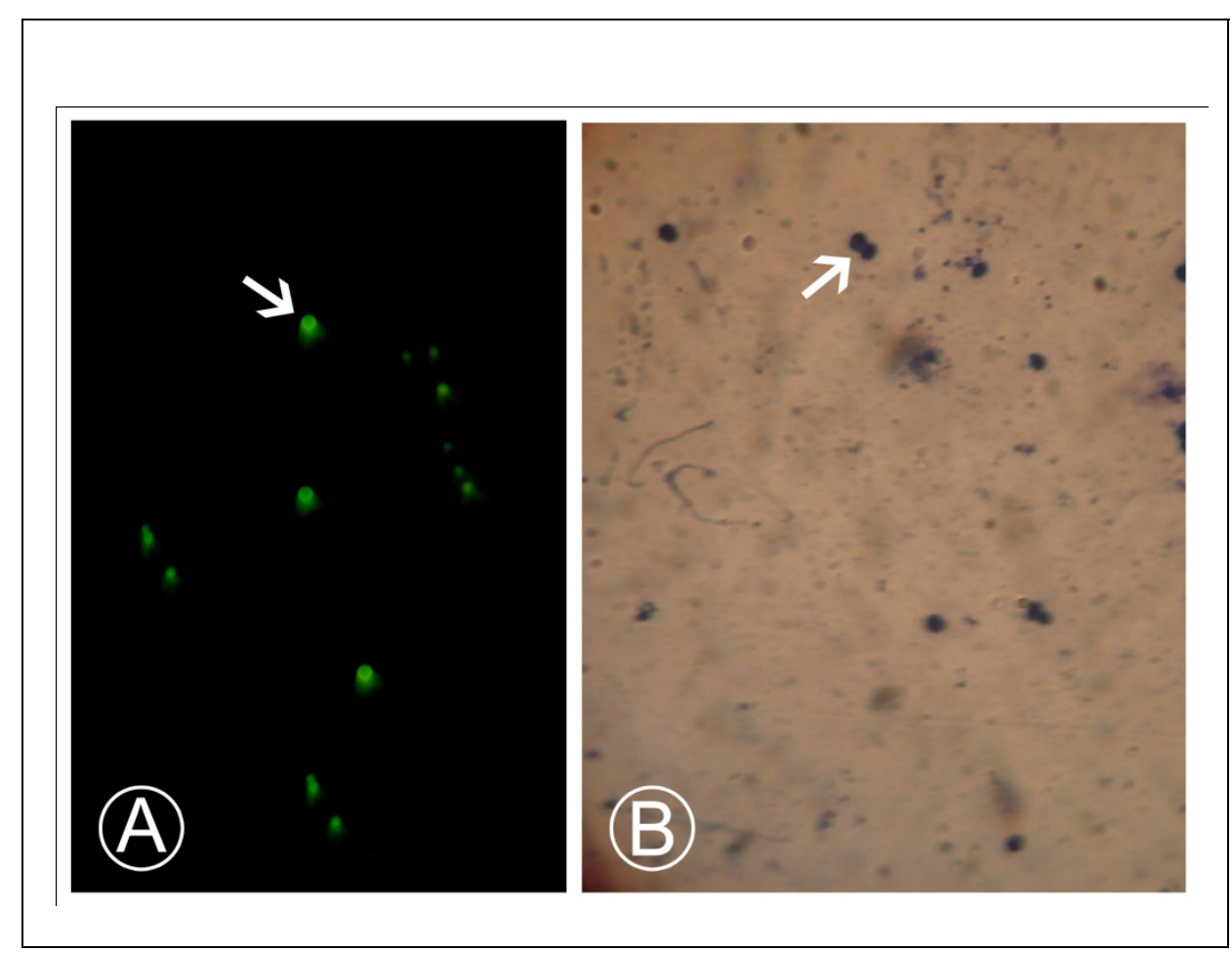

Figure 2. Direct examination of the clinical specimens (saliva) showing budding yeast cell in:

A- $20 \% \mathrm{KOH}$ mounting with calcofluor stain under fluorescent microscope 40X lens (arrowed).

B- Gram 's staining smear under 100X lens (arrowed). 


\section{Discussion}

Candida establish a biological link with the host which guarantees their saprophytic condition by establishing an ecological equilibrium denoted "amphibionts". When this equilibrium is broken due to different endogenous and/or exogenous factors, these amphibionts behave as opportunistic microorganisms and can invade tissues and cause oral candidiasis or lifethreatening disease in patients whose immune defenses have been altered by different factors ${ }^{14}$.

Eighty seven $(72.5 \%)$ cancer and diabetic patients revealed budding yeast cells in their saliva in comparison to $18(30 \%)$ healthy control. LotfiKamran and Coworkers (2009); Afraseyabi and Coworkers (2011) ${ }^{15}$ reported that a higher colonization of Candida species was seen in diabetic and cancer patients compared to the control group. Furthermore, the carriage rate for Candida is hard to give since it depends on the age and health of the population studied ${ }^{16}$, but a range from $17 \%-75 \%$ has been reported ${ }^{17}$.

From the $52.9 \%$ cancer patients and $47.1 \%$ diabetic patients, Candida species were identified in $93.1 \%$ of the total isolated yeasts, while nonCandida species or other yeasts formed $6.9 \%$. These results were confirmed by Al-Attas and Amro (2010) as they indicated that the most isolated yeasts were Candida species (93.3\%), and the other yeasts were $(6.7 \%)$. Over the past decades, numerous surveys have documented an increase rate of fungal infection among both oncology and non-oncology patients and the most common isolates were Candida species $^{19}$.

\section{The isolated yeasts and their densities from cancer and diabetic patients}

The 90 yeast isolates that were identified during the study included 48 isolates from cancer patients and 42 from diabetic ones with no significant difference between the two groups by using Chi-square test

0.281). This is due to the immunosuppressive status of the patients of the two groups as mentioned by other investigator who stated that Candidal colonization and infection occur in close association with chemotherapy for cancer, immune dysfunction, and malnutrition ${ }^{20}$.

A higher frequency of yeasts were detected in the saliva of both cancer and diabetic patients $(53.3 \% ; 46.7 \%$ respectively) table 2 . Other study reported that the frequency of yeasts in saliva of cancer patients were $31.6 \%$, while from diabetic patients were 75.7 $\% 15,21$. The hyposalivation and xerostomia are considered a common complaint by diabetic and cancer patients especially after chemotherapy, which predispose the oral mucosa to opportunistic infection by Candida species ${ }^{9}$.

All the diabetic patients that were studied had a level of glucose in their blood higher than $200 \mathrm{mg} / \mathrm{dl}$, (HbA1C $>$ 9.2). This is confirmed by other investigators who reported that the predisposition of diabetic patients to Candida overgrowth has been explained in terms of the enhancement of yeast growth by elevated glucose level $^{22}$.

A significant difference was recorded during the current study between the density ( $\mathrm{CFU} / \mathrm{ml}$ ) of the yeasts in saliva $($ mean $=10020.1)$ of the patients, and saliva $($ mean $=772.2)$ of the control group by t-test (p 0.001). These results showed that the carriage rate and density of the yeasts was influenced significantly by 
systemic factors such as the disease types of the studied patients. Other investigators reported the risk factors for Candidal infection in cancer and diabetic patients are complex ${ }^{18}$. On the other hand, the higher mean of Candidal density was detected in the saliva of the studied diabetic patients (14518.3 CFU/ml ) in comparison to cancer patients $(6010.9 \mathrm{CFU} / \mathrm{ml})$. This may be due to the long duration of diabetes mellitus patients as recorded in the request forms during the study (Fig 1).

\section{Candida species}

Out of the 84 isolates of Candida species, $74.4 \%$ were C.albicans which showed a significant difference in their presence in comparison to the other Candida and non-Candida yeast species. These results were confirmed by other investigators who stated that C.albicans alone outnumbered other species and accounted for $73.7 \%{ }^{15}$. Meruman and Coworkers (2007) reported that the most frequent encountered species are C.albicans, and non-Candida albicans species are isolated in increasing number in medically compromised patients. In the control group, Candida albicans also appeared as the main isolate (94.4\%) from the 18 healthy individuals. This keeping with other reports that the most common species isolated from the oral cavity of both healthy and diseased cases is C.albicans .

\section{Antifungal susceptibility test}

Antifungal susceptibility tests are now required to optimize antifungal treatment which gives the emergence of antifungal resistance in some Candida species ${ }^{24}$.

From the data outlined in the results, it was evident that amphotericin B constituted the first choice drug for the treatment of yeasts infection caused by Candida and non-
Candida yeasts species. These results were in agreement with $\operatorname{Kabli}(2008)^{25}$ and Bernal-Martinez et al., $(2010)^{26}$ that reported amphotricin $\mathrm{B}$ in vitro was the most active drug against yeast species. The others most effective antifungal drugs were nystatin, ketoconazole and voriconazole. The least effective antifungal agents against C. albicans were fluconazole and itraconazole. On the other hand, the isolated Candida species from control group showed good sensitivity to all the 6 antifungal agents. Fluconazole has been widely used for the prophylaxis and the treatment of different types of candidiasis because its low toxicity and the ease of administration, but it can be associated with a shift of species and resistance pathogens ${ }^{27}$. Magaldi and Coworkers $(2001)^{28}$ found that $9.8 \%$ and $4.9 \%$ of C. albicans isolated from patients with no previous antifungal treatment were resistant to fluconazole and itraconazole respectively, which increased to $44.7 \%$ and $44.15 \%$ after treatment with these drugs.

In conclusion: the direct yeast identification procedures and culture, in addition to biochemical tests, identify different yeasts in $72.5 \%$ $(87 / 120)$ of the immunocompromised patients from their saliva. Eight Candida species and 4 non-Candida species have been identified. The apparently healthy control group showed 2 Candida species isolates in $30 \%(18 / 60)$ of them. The antifungal susceptibility test was done for the first time and showed a good response to amphotericin B but increasing resistance to fluconazole and have been controlled. The increasing growth and density of yeasts in the immunocompromised patients in comparison to the control group, is considered a risk factor for the infection by these species, and has be 
to controlled by effective antifungal agents.

\section{References}

1. Lotfi-Kamran MH, Jafari AA, Falah-Tafti A, Tavakoli E, Falahzadeh MH. Candida colonization on the denture of diabetic and non-diabetic patients. Dent Res J. 2009; 6(1): 23-27.

2. Sahin I, Oksuz S, Sencan I, Glucan A ,Karabay O, Glucan E, et al. Prevalence and risk factors for yeast colonization in adult diabetic patients. Ethiop Med J. 2005; 43: 103-109.

3. Alexander JW, Boyce ST, Babcock GF, Gianotti L, Peck MD, Dunn DL, et al . The process of microbial translocation. Ann Surg. 1990; 212(4): 496-512.

4. Naglik JR, Challacombe SJ, Hube B. Candida albicans secreted aspartyl proteinases in virulence and pathogenesis. Microbiol Mol Biol Rev. 2003; 67(3): 400-428.

5. Pappas PG, Rex JH, Lee J, Hamill RJ, Larsen RA, Powderly W, et al. A prospective observational study of candidemia: epidemiology, therapy, and influences on mortality in hospitalized adult and pediatric patients. Clin Infect Dis. 2003; 37(5): 634-643.

6. Kumar BV, Padshetty NS, Bai KY, Rao MS. Prevalence of Candida in the oral cavity of diabetic subjects. JAPI. 2005; 53: 599-602.

7. Odds FC, Evans EGV, Taylor MAR, Wales JK. Prevalence of pathogenic yeasts and humoral antibodies to Candida in diabetic patients. J Clin Pathol. 1978; 31: 840-844.

8. El-Mahallawy HA, Attia I, Ali-ElDin NH, Salem AE, Abo-El-Naga S. A prospective study on fungal infection in children with cancer. $\mathrm{J}$ Med Microbiol. 2002;51: 601-605.

9. Toscano N, Holtzclaw D, Hargitai IA, Shumaker N, Richardson $\mathrm{H}$, Naylor G, et al. Oral implication of cancer chemotherapy. J Impl Adv Clin Dent. 2009;1(5): 51-69

10. Forbes BN, Sahm DF, Weissfield AS (2002). Bailey and Scott's Diagnostic Microbiology, 9th Ed. M Mosby. St. Louis London Philadelphia Sydney Toronto. 2002; Chapter 53 pp. 724-785.

11. Murray PR, Rosenthal KS, Pfaller MA. Medical Microbiology 5th ed. Elsevier Mosby. Philadelphia. 2005; Section 6 pp. 782-787.

12. Winn WC, jr., Allen SD, Janda WM, Koneman's EW, Procop G, Schreckenberger PC, et al. Koneman's color atlas and text book of diagnostic microbiology. 6th ed. Lippincott Williams and Wilkins. Philadelphia . 2006; chapter 21. pp.1219-1230.

13. Nobile CJ, Bruno VM, Richard ML, Davis DA, Mitchell PA. Genetic control of chlamydospore formation in Candida albicans. Microbiol.2003;149(12):3629-637.

14. Soysa NS, Smaranayake LP, Ellepola AN. Diabetes mellitus as a contributory factor in oral candidiasis. Diabet Med. 2006; 23(5): 455-459.

15. Afraseyabi S, Afkhamzadeh A, Sabori H, Verdi F,Khaksar N, Mosavei B, et al. Oral candidiasis amongst cancer patients at Qods 
hospital in Sanadaj. Afr J Clin Exper Microbiol.2011;12(3):129132.

16. Cannon RD, Chaffin WL. Oral colonization by Candida albicans. Crit Rev Oral Biol Med. 1999; 10(3): 359-383.

17. Nittayananta $W$, Jealae S, Winn T. Oral Candida in HIV-infected heterosexual and intravenous drugs users in Thailand. J Oral Pathol Med. 2001; 30(6): 347-354.

18. Al-Attas SA, Amro SO. Candidal colonization, strain diversity, and antifungal susceptibility among adult diabetic patients. Ann Saudi Med. 2010; 30(2): 101-108.

19. Wingard JR. Importance of Candida species other than C. albicans as pathogens in oncology patients. Clin Infect Dis. 1995; 20: 115-125.

20. Azoulay E, Cohen Y, Zahar JR, Garrouste-Orgeas M, Adrie C, Moine $\mathrm{P}$, et al . Practices in nonneutropenic ICU patients with Candida positive airway specimens. Intens Care Med. 2004; 30(7): 1384-1389.

21. Yellamma bai $K$, Vinod $K B$. Prevalence of Candida species in the oral cavity of diabetic and nondiabetic subjects in gulbarga district, Karnataka. Ann Essen Den. 2010; 2(4): 6-9.

22. Barbeau J, Seguin J, Goult JP, de Koninck L, Avon SL, Lalonde B et al. Reassessing the presence of Candida albicans in denature related stomatitis. Oral Surg Oral Med Oral Pathol Oral Radiol Endod. 2003; 95(1): 51-59.

23. Meurman JH, Siikala E, Richardson M, Rautemaa R. Non-
Candida albicans Candida yeasts of the oral cavity. Communicating Current Res Edu Top Tre Appl Microbiol A.Mendez-Vilas (Ed.) 2007; 719-731.

24. Bourgeois N, Dehandschoewecker L, Bertout S, Bousquet PJ, Rispail P,Lachaud L.Antifungal susceptibility of 205 Candida spp. isolated primarily during invasive candidiasis and comparison of the Vitek2 system with CLSI broth microdilution and $\mathrm{E}$ test methods. J Clin Microbiol.2010;48(1):154-161.

25. Kabli SA. In vitro, susceptibilities of clinical yeast isolates to antifungal drugs of polyene, pyrimidine, and azoles, and their effect in yeast adhesion and mycelia formation. Saudi J Biol Sci. 2008; 15(2): 189-198.

26. Bernal-Martinez L, Gomez-Lopez A, Castelli MV, Mesa-Arango AC, Zaragoza O, RodriguezTudela JL, et al susceptibility profile of clinical isolates of non Cryptococcus neoformans/nonCryptococcus gattii Cryptococus species and literature review. Med Mycol. 2010; 48(1): 90-96.

27. Badiee P, Alborzi A, Davarpanah MA, Shakiba E. Distributions and antifungal susceptibility of Candida species from mucosal sites in HIV positive patients. Arch Ira Med.2010;13(4):282-287.

28. Magaldi S, Mata S, Hartung C, Verde G, Deibis L, Roldan Y, et al. In vitro susceptibility of 137 Candida species isolates from HIV positive patients to several antifungal drugs. Mycopathologia. 2001; 149(2): 63-68. 